\title{
EVALUATION OF DISSIPATION MECHANISMS FOR PYRENE BY MAIZE (ZEA MAYS L.) IN CADMIUM CO-CONTAMINATED SOIL
}
H. ZHANG ${ }^{1,2,3}$
Z. DANG ${ }^{1,2, *}$
X.Y. YI $\mathrm{I}^{1,2}$
C. YANG ${ }^{1,2}$
L.C. ZHENG ${ }^{1,2}$
G.N. $\mathbf{L U}^{1,2}$

\author{
${ }^{1}$ School of Environmental Science and Engineering \\ South China University of Technology \\ Guangzhou Higher Education Mega Center \\ Guangzhou 510006, P.R. China \\ ${ }^{2}$ The Key Lab of Pollution Control and Ecosystem \\ Restoration in Industry Clusters \\ Ministry of Education, Guangzhou Higher \\ Education Mega Center, Guangzhou 510006, China \\ ${ }^{3}$ School of Environmental Science and Engineering \\ Guilin University of Technology, Guilin 541004, China
}

Received: 01/03/09

Accepted: 20/10/09 *to whom all correspondence should be addressed: e-mail: chzdang@scut.edu.cn

\begin{abstract}
Sites co-contaminated with organic and metal pollutants are common and considered to be a more complex problem, as the two components often have a synergistic effect on cytotoxicity. This study investigated the dissipation mechnisms for pyrene in cadmium co-contaminated soil in which maize (ZEA MAYS L.) was grown in a greenhouse experiment. Results showed the growth response of maize may be affected by the co-contamination due to the interaction between the heavy metal and organic pollutants. Pyrene in both planted and unplanted soil diminished significantly at the end of 60 -day culture, accounting for $21-31 \%$ of the initial extractable concentration in unplanted soil and $12-27 \%$ in planted soil, which indicated that the dissipation of pyrene was enhanced by the presence of vegetation. Although the presence of cadmium stimulated the accumulation of pyrene in roots and shoots of maize, contributions of plant off-take of pyrene to the total remediation enhancement in the presence of vegetation was less than $0.3 \%$. A significant positive correlation was observed between soil enzyme activities (dehydrogenase, polyphenol oxidase) and the removal ratio of pyrene. Plant root exudates appear to promote the number of rhizosphere microorganisms and enzyme activity, thereby improving biodegradation of pyrene.
\end{abstract}

KEYWORDSphytoremediation; compound contamination; heavy metal ; PAHs.

\section{INTRODUCTION}

Intense industrial activity in the 20th century has been particularly deleterious to our environment, resulting in a large number and variety of pollutants. It was reported that forty percent of hazardous waste sites on the Environmental Protection Agency's (EPA) national priority list (NPL) are co-contaminated with organic and heavy metal pollutants (Sandrin and Maier, 2002). In natural soils, bioavailable heavy metals exhibit toxic activity towards soil biota which may lead to a decrease in the number and activity of soil microorganisms and reduce the rate of organics microbial transformations, which play an important role in the dissipation of these compounds in the soil environment (Amor et al., 2001; Maliszewska-Kordybach and Smreczak, 2003). There is also a possibility of synergistic activity of both groups of pollutants on soil biota. Thus, the presence of both types of contaminants at the same site presents technical and economic challenges for decontamination strategies.

One in situ decontamination approach showing promise for addressing both organic and 
inorganic contaminants is phytoremediation, which impose minimal environmental disturbance, and which offer economic, agronomic, and societal benefits (Garbisu and Alkorta, 2001). In heavy metal-organic pollutant combined systems, heavy metal not only exert direct effects on microorganisms and cause direct and indirect effects for the degradation of organic pollutants, but also cause positive or negative effects on root growth and thereafter affect root-enhanced dissipation. Plant may contribute to the dissipation of organics by plant uptake and accumulation, increase of microbial numbers or enzyme activiy, improvement of physical and chemical soil conditions. However, the impact of each process has not been clearly elucidated. The efficiency and mechanisms of phytoremediation of organic pollutants co-existing with heavy metals is complex and quite different from that in the single-pollutant system. Therefore, a more thorough understanding of the mechanisms by which metals affect the dissipation of organic pollutants in the planted soils is needed.

This study was conducted to investigate the dissipation mechanisms for pyrene in cadmium co-contaminated soil by maize in a greenhouse experiment. Pyrene was used as the model organic in this study because it represents a class of organic compounds, polyaromatic hydrocarbons, with carcinogenic potential that is present at many Superfund sites. Cadmium was chosen as the metal as it is the second most common metal found at Superfund sites, and is one of the ten high-priority pollutants. Screening of effective plant species was performed prior to this study. A species was chosen for its ability to extract heavy metals, remove PAH and having a high-biomass when grown on the tested soils. In our previous work (zhou et al., 2005,2007 ), it was found that maize CT38 could normally grow and effectively extract metals in multi-metal $(\mathrm{Cu}, \mathrm{Cd}, \mathrm{Pb}$ and $\mathrm{Zn})$ contaminated soils from Daobaoshan mine, located in the north of Guangdong province, China. In our greenhouse trials, it has also been demonstrated that maize CT38 was a promising crop for phytoremediation of soils co-contaminated with cadmium and pyrene because of its luxuriant root system, its high-biomass and its adaptability.

\section{METHODS}

\subsection{Soil treatment}

Soil was collected from the top layer $(0-20 \mathrm{~cm})$ of an agricultural field with $\mathrm{pH} 6.42$ and $1.63 \%$ organic matter in Zengcheng county, Guangdong province, China. The soil with no detectable pyrene and $0.13 \mathrm{mg}$ cadmium $\mathrm{kg}^{-1}$ soil was used in this study. The soil was air-dried and sieved through a $3 \mathrm{~mm}$ mesh. The levels of cadmium and pyrene added into the soil were 0 , 2.0, $4.5 \mathrm{mg}$ cadmium $\mathrm{kg}^{-1}$ soil and $0,10,50,100 \mathrm{mg}$ pyrene $\mathrm{kg}^{-1}$ soil. Briefly, the bulk soil was first mixed thoroughly with cadmium $\left(\mathrm{as} \mathrm{CdCl}_{2}\right.$ ) in an aqueous solution and incubated at a moisture condition for 2 weeks. Subsamples containing pyrene was prepared with the above material. Soils were spiked with a mixture of high purity pyrene in acetone. After the acetone had evaporated, the spiked soils were then sieved again through a $3 \mathrm{~mm}$ mesh to ensure homogeneity and stored for use. Treated soils were then packed into pots (4kg dry weigh soil per pot), and placed in a glass greenhouse at $60 \%$ of the soil water holding capacity.

\subsection{Experimental design}

Pregerminated seeds of maize CT38 (Zea mays L.) were sown in each pot. The seedlings were thinned 5-7 days after emergence to leave one plant per pot. Each treatment was repeated in triplicate, and the treated pots were randomized in the greenhouse and places exchanged every second day. Soils were carefully watered as needed and fertilized with NPK fertilize mixture ( $1 \mathrm{~g} \mathrm{~kg}^{-1}$ of soil) containing $\mathrm{N}: \mathrm{P}_{2} \mathrm{O}_{5}: \mathrm{K}_{2} \mathrm{O}=1: 0.35: 0.8$. The experiment continued to 60 days.

\subsection{Sampling and analysis}

Pots were left without watering for 1 day prior to harvests (60 days after seeding). At harvest, shoots were cut at the soil surface, dried and weighed. The upper 2-5 mm of soil in each pot was discarded. By further gently crushing the soil and shaking the roots, the portion of soil obtained in this manner was also discarded, which account for $70-80 \%$ of soil mass. Soil obtained by continued vigorous rubbing and shaking of the root system was classified as strongly adhering soils or 'planted soil', which account for $10-15 \%$ of the soil. 'Unplanted soil' was obtained in a similar way. Soils and plants for analysis of chemical or enzymatic activity were stored at $-20{ }^{\circ} \mathrm{C}$ and $4{ }^{\circ} \mathrm{C}$ respectively. 
The procedure used to extract PAHs was a modification of those of Kipopoulou et al. (1999) and Gao et al. (2004). Sample preparation included homogeneous mixing of $2 \mathrm{~g}$ of soil sample with anhydrous $\mathrm{Na}_{2} \mathrm{SO}_{4}$ to remove moisture and ultrasonication in $10 \mathrm{ml}$ of dichloromethane for $1 \mathrm{~h}$ followed by centrifugation. Then $3 \mathrm{ml}$ of supernatant was filtered through $2 \mathrm{~g}$ of silica gel column with $11 \mathrm{ml}$ 1:1 elution of hexane and dichloromethane. The solvent fractions were then evaporated, and exchanged by methanol with a final volume of $2 \mathrm{ml}$. Plant samples were extracted by ultrasonication for $1 \mathrm{~h}$ in enough 1:1 solution of acetone and hexane. The solvent fractions passed through an anhydrous $\mathrm{Na}_{2} \mathrm{SO}_{4}$ column with elution of 1:1 acetone and hexane. The solvents were then evaporated and exchanged to $2 \mathrm{ml}$ hexane, followed by filtration through $2 \mathrm{~g}$ of silica gel column with $11 \mathrm{ml}$ of 1:1 elution of hexane and dichloromethane. The samples were then evaporated and exchanged by methanol with a final volume of $2 \mathrm{ml}$. After filtration through $0.22 \mu \mathrm{m}$ filter units, the treated soil and plant tissue extracts were analyzed with a high-performance liquid chromatograph fitted with a $4.6 \times 250 \mathrm{~mm}$ reverse phase C18 column using methanol-water (85:15) as the mobile phase at a flow rate of $1 \mathrm{ml} \mathrm{min}^{-1}$. Chromatography was performed at $30^{\circ} \mathrm{C}$. Pyrene was detected at $238 \mathrm{~nm}$.

Activity of soil dehydrogenase was estimated as described by Casida et al. (1964) with a minor modification. Five grams of soil was mixed with $10 \mathrm{ml}$ of $0.25 \%$ aqueous triphenyltetrazolium chloride (TTC) and incubated in a sealed tube at $30^{\circ} \mathrm{C}$ for $6 \mathrm{~h}$. The absorbance at $485 \mathrm{~nm}$ of methanol extracts of the triphenylformazan (TPF) produced was then measured using methanol as a blank. The activity of dehydrogenase was expressed as $\mathrm{mg} \mathrm{TPF}^{-1}$ dry soil 6 $\mathrm{h}^{-1}$. Soil polyphenol oxidase activity was measured by the colorimetric method based on the purpurogallin formation in the pyrogallic acid-amended soil sample (after $3 \mathrm{~h}$ of incubation at $30^{\circ} \mathrm{C}$ ) and expressed as $\mathrm{mg}$ purpurogallin $\mathrm{g}^{-1}$ dry soil $3 \mathrm{~h}^{-1}$ (Ma et al., 2003).

\subsection{Data processing}

Results are presented as the average of three replicates. Statistical analyses were carried out using analysis of variance (ANOVA) or paired $t$-tests. The level of statistical significance is represented by * for $p<0.05$, ** for $p<0.01$ and ns for not significant.

\section{RESULTS AND DISCUSSION}

\subsection{Plant biomass}

At the end of the 60-day growth, despite a reduction in dry weight for some of the polluted soils (Table 1), plants formed dense root systems and luxuriant aerial growth in the spiked soils.

Table 1. Plant dry weight of maize as affected by the co-contamination of pyrene and cadmium

\begin{tabular}{ccccc}
\hline $\begin{array}{c}\text { Treatment } \\
\text { No. }\end{array}$ & $\begin{array}{c}\text { Pyrene added } \\
\left(\mathrm{mg} \mathrm{kg}^{-1}\right)\end{array}$ & $\begin{array}{c}\text { Cd added } \\
\left(\mathrm{mg} \mathrm{kg}^{-1}\right)\end{array}$ & $\begin{array}{c}\text { Root } \\
(\mathrm{g})\end{array}$ & $\begin{array}{c}\text { Shoot } \\
(\mathrm{g})\end{array}$ \\
\hline A1 & 0 & 0 & $3.12 \pm 0.13$ & $12.95 \pm 0.57$ \\
A2 & 10 & 0 & $3.00 \pm 0.26$ & $13.23 \pm 1.05$ \\
A3 & 50 & 0 & $3.04 \pm 0.24$ & $13.07 \pm 0.68$ \\
A4 & 100 & 0 & $2.97 \pm 0.35$ & $13.00 \pm 0.95$ \\
B1 & 0 & 2.0 & $2.88 \pm 0.31$ & $12.83 \pm 0.99$ \\
B2 & 10 & 2.0 & $2.83 \pm 0.32$ & $12.93 \pm 0.88$ \\
B3 & 50 & 2.0 & $2.80 \pm 0.40$ & $12.76 \pm 1.00$ \\
B4 & 100 & 2.0 & $2.73 \pm 0.38$ & $12.90 \pm 0.89$ \\
C1 & 0 & 4.5 & $2.63 \pm 0.10$ & $12.10 \pm 0.61$ \\
C2 & 10 & 4.5 & $2.53 \pm 0.15$ & $12.24 \pm 0.59$ \\
C3 & 50 & 4.5 & $2.57 \pm 0.20$ & $12.30 \pm 0.61$ \\
C4 & 100 & 4.5 & $2.54 \pm 0.25$ & $12.28 \pm 0.52$ \\
\hline
\end{tabular}

Two-way ANOVA. Values are means \pm S.E. Root: $F=8.677, \mathrm{P}<0.01$; pyrene: ns; cadmium: ${ }^{*}$. Shoot: $F=3.507, P<0.05$; pyrene: ns; cadmium: *.

There was a slight but non-significant $(p<0.05)$ decrease in roots and shoots dry weights in the pyrene spiked soils compared with that for the un-spiked soils. However, a more significant decrease in roots and shoots dry weights was observed in the cadmium spiked soils. Pyrene co-contamination slightly decreased the roots dry weights further with increasing concentration 
of pyrene in co-contaminated soil, which suggested that pyrene co-contamination could exert synergistic toxic effects on plant growth. These results were different to those of Lin et al. (2006), who reported that with the initial concentration of $50 \mathrm{mg} \mathrm{kg}^{-1} \mathrm{PCP}$, no outward signs of phytotoxicity or even better growth for ryegrass and radish were shown with the increment of soil $\mathrm{Cu}$ level. They also observed that certain concentrations of pyrene can alleviate the inhibition of $\mathrm{Cu}$ on maize (Lin et al. 2008). Perhaps plant species and the characteristics of pollutants cause different growth response of plants to organic or organic-heavy metal co-contamination.

\subsection{The dissipation of soil pyrene}

Pyrene in both planted and unplanted soil was greatly decreased at the end of the 60-day experiment, accounting for $21-31 \%$ of the initial extractable concentration in unplanted soil and $12-27 \%$ in planted soil. As shown in Fig.1, the extractable pyrene in the planted soil was significantly lower than that in the unplanted, which confirmed the beneficial effect of vegetation. For example, it was observed that the extractable pyrene in the co-contaminated soil (B2-B4) was $1.55,9.32,21.80 \mathrm{mg} \mathrm{kg}^{-1}$ in the planted soils where $10,50,100 \mathrm{mg} \mathrm{kg}^{-1}$ pyrene had been added, respectively; it was $2.47,12.97,27.09 \mathrm{mg} \mathrm{kg}^{-1}$, respectively, in unplanted soil. Maize enhanced the remediation of soil pyrene contamination in both sole pyrene pollution and pyrene-cadmium co-contaminated soil.

Contrasting the pyrene-alone pollution and pyrene-cadmium compound contamination indicated that, whether or not maize was planted, the residual pyrene in soil tended to increase with increased cadmium level. Fig. 2 shows the effect of cadmium on the pyrene dissipation in the planted soil. For example, the residual extractable pyrene was $1.12,7.39,17.45 \mathrm{mg} \mathrm{kg}^{-1}$ in the pyrene-alone contaminated planted soils with the treatment of $10,50,100 \mathrm{mg} \mathrm{kg}^{-1}$ pyrene, respectively. With increased cadmium level, it was observed that the extractable pyrene in the $2.0 \mathrm{mg} \mathrm{kg}^{-1}$ cadmium treatment soils was $1.55,9.32,21.80$, respectively, and 1.86, 10.90, $26.38 \mathrm{mg} \mathrm{kg}^{-1}$ in the $4.5 \mathrm{mg} \mathrm{kg}^{-1}$ cadmium treatment soils.

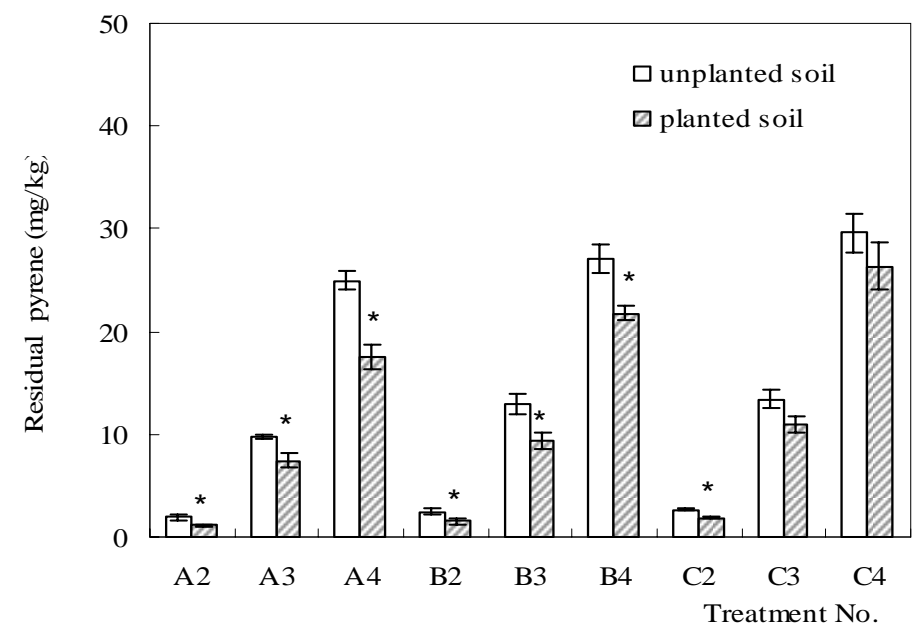

Figure 1. Residual concentration of pyrene in unplanted and planted soils *indicated significant different between un planted and planted treantement

Phytoremediation of organics is primarily based on the beneficial effects of roots on biodegradation. The increase residual concentration of pyrene in the presence of cadmium was probably attributed to changes in microbial composition, microbial activity and root physiology. Kuo and Genthner (1996) reported that metals adversely affecting degraders in a consortium. Addition of low levels of metals (0.1-0.2 $\mathrm{mg}$ total metal $\mathrm{L}^{-1}$ ) lengthened acclimation periods and decreased dechlorination and biodegradation rates. As known, changes in quality and quantity of root exudates would influence the degradation of xenobiotics, which was a microbially mediated process. Olson et al. (2003) proposed that differences in the quantity and quality of nutrients released by root exudation and root mortality likely lead to variable and potentially opposing effects on microbial PAH degradation. 


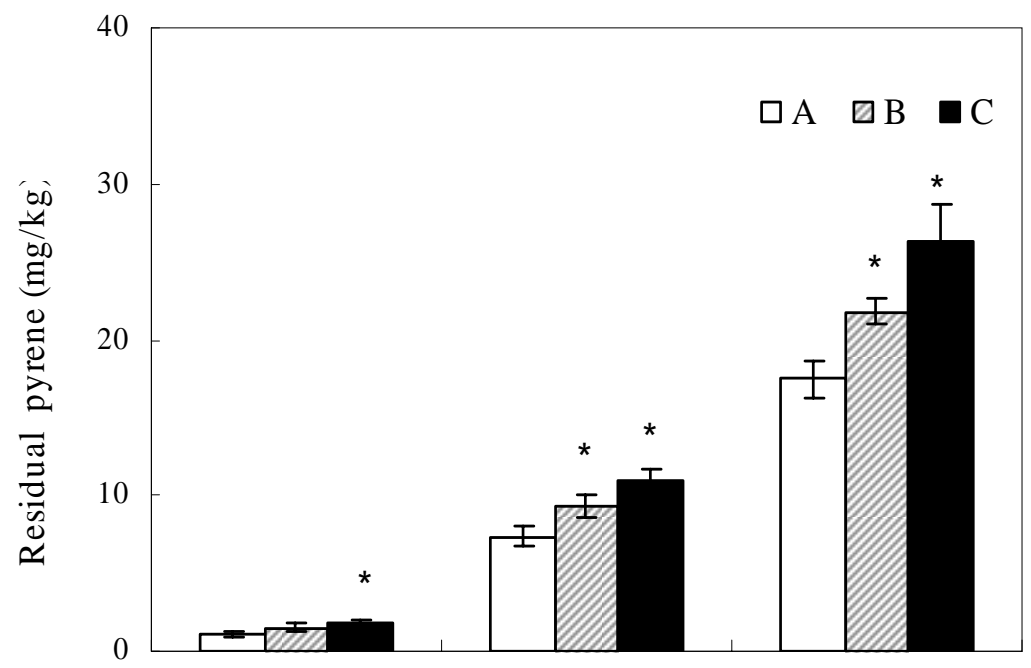

Figure 2. Residual concentration of pyrene in planted soils as affected by co-contaminated of cadmium

(A: no cadmium; B:cadmium 2.0mg/kg; C: cadmium $4.5 \mathrm{mg} / \mathrm{kg}$

*indicate significant different between $A$ and cadmium treatment)

In this experiment, we also observed an important phenomenon: in the presence of a high concentration of cadmium $\left(4.5 \mathrm{mg} \mathrm{kg}^{-1}\right)$, there was no significant difference in the pyrene concentration between the planted soil and unplanted soil with the initial pyrene concentration of 50 and $100 \mathrm{mg} \mathrm{kg}^{-1}$ (as shown in Fig.1). These results were similar to that of Lin et al. (2008). They observed that in the presence of a high concentration of $\mathrm{Cu}\left(>200 \mathrm{mg} \mathrm{kg}^{-1}\right)$, the pyrene residual was even higher in the planted soil than that in the non-planted soil. In our opinion, the presence of mass flow and the lowered biodegradation for pyrene in the high level cadmium co-contamination were probably responsible for the small difference between the planted soil and unplanted cadmium-contaminated soil. Plant water uptake induced a mass flow of pyrene towards the root zone of enhanced microbial activity and conditions that favor pyrene dissipation. This explanation can be supported by the results of Liste and Alexander (2000). They suggested that PAH mobilization under plants has occurred because as much as $205 \%$ more butanol-extractable pyrene was detected in a sterile fescue rhizosphere than in unplanted soil. When the mass flow occurred in the high cadmium co-contaminated planted soil, with pyrene flowing toward the root zone of the maize, the larger residual pyrene existed in the strongly adhering soils or planted soil. Because a high cadmium level inhibited the biodegradation of pyrene, the residual pyrene carried by mass flow in the rhizosphere or planted soil may be similar to that in unplanted soil, or even higher. Cadmium is one of the most toxic heavy metal pollutants, and the negative effect of $\mathrm{Cd}$ on the dissipation of organic pollutants should be fully considered.

\subsection{Plant uptake and accumulation of pyrene}

Pyrene contents in the roots and shoots of maize, at the end of the 60-day experiment, as a function of the residual pyrene concentration in soil, are listed in Table 2. These results indicate that the accumulation of pyrene in roots and shoots increased consistently with an increment in the soil residual pyrene concentration. However, the concentrations of pyrene in shoots were statistically far lower than in roots.

Concentrations of pyrene in roots grown in unspiked control soil were not detectable. But it was notable that even when shoots were grown in an unspiked control soil, accumulation of pyrene was detected in the shoots (Table 2). The concentrations of pyrene in shoots grown in soil $\mathrm{A} 1$ were $0.73 \mathrm{mg} \mathrm{kg}^{-1}$, which can only have derived from shoot uptake and accumulation from the atmosphere, probably through the retention of the vapor phase of pyrene on the waxy leaf cuticle (Trapp et al., 1990; Polder et al., 1995). This indicates that the shoot uptake of pyrene from the ambient air, possibly originally volatilized from the soils, was a pathway for pyrene intake by the above-ground parts of vegetables. Thus, the pyrene in shoots grown in 
spiked soil should be approximately the sum of the accumulation from air (denoted as the concentrations of pyrene in plant shoot grown in soil A1) and the translocation from roots.

Table 2. Pyrene contents in the roots and shoots of maize

\begin{tabular}{|c|c|c|c|c|c|}
\hline \multirow{2}{*}{$\begin{array}{l}\text { Treatment } \\
\text { No. }\end{array}$} & \multirow{2}{*}{$\begin{array}{l}\text { Residual } \\
\text { pyrene } \\
\text { in planted } \\
\text { soil } \\
\left(\mathrm{mg} \mathrm{kg}^{-1}\right)\end{array}$} & \multicolumn{2}{|c|}{$\begin{array}{l}\text { Accumulation concentration } \\
\left(\mathrm{mg} \mathrm{kg}^{-1}\right)\end{array}$} & \multicolumn{2}{|c|}{$\begin{array}{l}\text { Accumulation amount } \\
\left.(\mu \mathrm{g} \mathrm{pot})^{-1}\right)\end{array}$} \\
\hline & & Root & Shoot & Root & shoot \\
\hline A1 & $N D^{a}$ & $\mathrm{ND}^{\mathrm{a}}$ & $0.73 \pm 0.10$ & $\mathrm{ND}^{\mathrm{a}}$ & $9.53 \pm 1.77$ \\
\hline A2 & $1.12 \pm 0.13$ & $7.40 \pm 0.44$ & $4.09 \pm 0.39$ & $22.25 \pm 3.11$ & $54.41 \pm 6.18$ \\
\hline A3 & $7.39 \pm 0.72$ & $21.90 \pm 1.50$ & $10.06 \pm 0.86$ & $66.73 \pm 8.12$ & $131.23 \pm 9.29$ \\
\hline A4 & $17.45 \pm 1.20$ & $28.62 \pm 1.86$ & $12.44 \pm 0.94$ & $84.62 \pm 8.04$ & $161.24 \pm 7.15$ \\
\hline B1 & $N D^{a}$ & $N D^{a}$ & $0.59 \pm 0.13$ & $N D^{a}$ & $7.70 \pm 1.18$ \\
\hline B2 & $1.55 \pm 0.27$ & $9.12 \pm 0.62$ & $4.33 \pm 0.31$ & $25.92 \pm 4.57$ & $56.22 \pm 4.67$ \\
\hline B3 & $9.32 \pm 0.78$ & $24.15 \pm 1.77$ & $10.95 \pm 0.70$ & $67.25 \pm 6.66$ & $139.40 \pm 6.79$ \\
\hline B4 & $21.80 \pm 0.78$ & $31.68 \pm 3.11$ & $13.78 \pm 0.94$ & $85.96 \pm 7.06$ & $177.27 \pm 9.08$ \\
\hline B2 & $N D^{a}$ & $N D^{a}$ & $0.66 \pm 0.08$ & $N D^{a}$ & $7.96 \pm 1.23$ \\
\hline $\mathrm{C} 2$ & $1.86 \pm 0.16$ & $10.00 \pm 1.07$ & $5.00 \pm 0.35$ & $25.43 \pm 4.26$ & $61.35 \pm 6.15$ \\
\hline C3 & $10.90 \pm 0.81$ & $27.17 \pm 1.35$ & $12.03 \pm 0.98$ & $69.83 \pm 8.08$ & $147.65 \pm 8.27$ \\
\hline C4 & $26.38 \pm 2.23$ & $35.14 \pm 2.30$ & $15.73 \pm 0.84$ & $89.06 \pm 9.85$ & $193.07 \pm 9.85$ \\
\hline
\end{tabular}

Values are means \pm S.E. ${ }^{a}$ not detectable.

Although shoots apparently accumulated pyrene from air, the concentrations of pyrene in shoots grown in spiked soils were much larger than the shoot uptake and accumulation of pyrene in the unspiked control soil $\mathrm{A} 1$ (Table 2). This demonstrated that the translocation of pyrene from roots to shoots was much more significant than the deposition of pyrene onto maize from the atmosphere. Since pyrene in the roots of maize grown in unspiked control soil A1 was not detectable, pyrene accumulated by shoots from the atmosphere were not transported to roots in any significant amount. These chemicals, when found in roots grown in various spiked soils, are derived from root uptake and accumulation.

It was observed that the uptake of pyrene in maize grown in soils co-contaminated with pyrene and cadmium was higher than that in soil contaminated with pyrene alone by $10.3 \%-35.1 \%$ in roots and $5.9 \%-26.5 \%$ in shoots. As mentioned above, for the same initial concentration of pyrene in soils, the residual concentrations of pyrene in co-polluted soils were higher than those in pyrene-only polluted soils because of the presence of cadmium. In our opinion, the accumulation of pyrene in maize from soil tended to increase with the level of their soil pyrene concentration, so the greater accumulation of pyrene in maize appeared in soils co-contaminated with pyrene and cadmium. On the other hand, the decreased biomass in the presence of cadmium may be responsible for the incremental bio-concentration effect. In this experiment, although the presence of cadmium stimulated the accumulation of pyrene in the roots and shoots of maize, the direct accumulation of pyrene in maize from spiked soils was always less than $282 \mu$ pot $^{-1}$, which is less than $0.3 \%$ of the total dissipation of pyrene in the presence of vegetation.

\subsection{Soil enzyme activities}

Pollutants introduced into the soil exert an influence on the microbiota, which is manifested by changes in enzyme activity. Soil enzyme activities are the driving force behind all the biochemical transformations occurring in soil. Their evaluation may provide useful information on soil microbial activity and be helpful in establishing the effects of soil-specific environmental conditions (Andreoni et al., 2004). Enzymatic tests are also useful when studying the intensity of the remediation processes in the soils (Stanislaw et al., 2004). In our previous experiment on changes of four kinds of soil enzyme activity (Zhang et al., 2007), results showed that soil dehydrogenase and polyphenol oxidase enzyme activities were quite sensitive to pollution by cadmium and pyrene. This finding is supported by previous demonstrations that dehydrogenases activity appeared to be the most sensitive parameter for the measurement of 
soil biological properties (Maliszewska-Kordybach and Smreczak, 2003). In this experiment, changes of enzyme activities on soil dehydrogenase and polyphenol oxidase between unplanted and planted soil will be studied to estimate the vegetation effect and mechanisms for pyrene dissipation in the cadmium co-contaminated soil.

The enzyme activity in unspiked and unplanted soil was taken as the control value-100\%. As shown in Fig.3 and Fig.4, these two types of enzyme activities in unplanted soils co-contaminated by cadmium and pyrene were significantly lower than the control value, decreasing to on average of $66.7 \%$ for dehydrogenase and $63.3 \%$ for polyphenol oxidase of the control value. It tended to decline along with increase in soil pyrene and cadmium level. It was observed that a low concentration of pyrene alone contamination can increase these two enzyme activities slightly. For example, the activities of dehydrogenase and polyphenol oxidase in the unplanted spiked soil alone with $10 \mathrm{mg} / \mathrm{kg}$ pyrene reached $102.3 \%$ and $116.8 \%$ of the control value, respectively. However, with an increase in the cadmium level, the activities of dehydrogenase and polyphenol oxidase decreased to $76.0 \%$ and $73.6 \%$ of the control value in $2.0 \mathrm{mg} \mathrm{kg}-1$ cadmium treatment and $65.0 \%$ and $61.3 \%$ of the control value in $4.5 \mathrm{mg} \mathrm{kg}-1$ cadmium treatment, respectively. The results indicated that there is a synergistic inhibition of both the heavy metal and PAHs on soil biota. As Maliszewska-Kordybach et al. (2003) reported, inhibition of soil microbial parameters in many cases was stronger in soils contaminated with both groups of pollutants than in soils contaminated with a heavy metal or PAH alone.

The enzyme activity in planted soils were increased by on average by $11.0 \%$ for dehydrogenase over that in unplanted soil, and $18.4 \%$ for polyphenol oxidase. The higher level of enzyme activity in planted soil appears to be one explanation of why pyrene dissipates to a greater extent in planted soils than in unplanted soils. Dehydrogenase and polyphenol oxidase are two important kinds of redoxase in soils, which are the catalysts for important metabolic processes, including the decomposition of organic inputs and the detoxification of xenobiotics (Margesin et al., 2000). Kaimi et al (2006) reported that there was a significant correlation between the dissipation rate of diesel oil and soil dehydrogenase activity both in the rhizosphere and the root-free soil. This is similar to what was found in our experiment. Significant positive correlations were found between the enzyme activities of dehydrogenase or polyphenol oxidase and the removal ratio of pyrene in soils (Fig.5, Fig.6). R2 values for linear regressions were 0.8765 and 0.9183 for dehydrogenase, 0.8806 and 0.9410 for polyphenol oxidase, respectively, in planted and unplanted soil. Soil dehydrogenase and polyphenol oxidase activity were therefore found to be suitable for evaluating pyrene dissipation both in the pyrene-alone pollution and pyrene-cadmium co-contamination. This finding is supporting by previous demonstrations of a correlation between soil dehydrogenase activity and the potential for biodegradation in the bioremediation of petroleum contaminated soils (Namkoong et al., 2002).

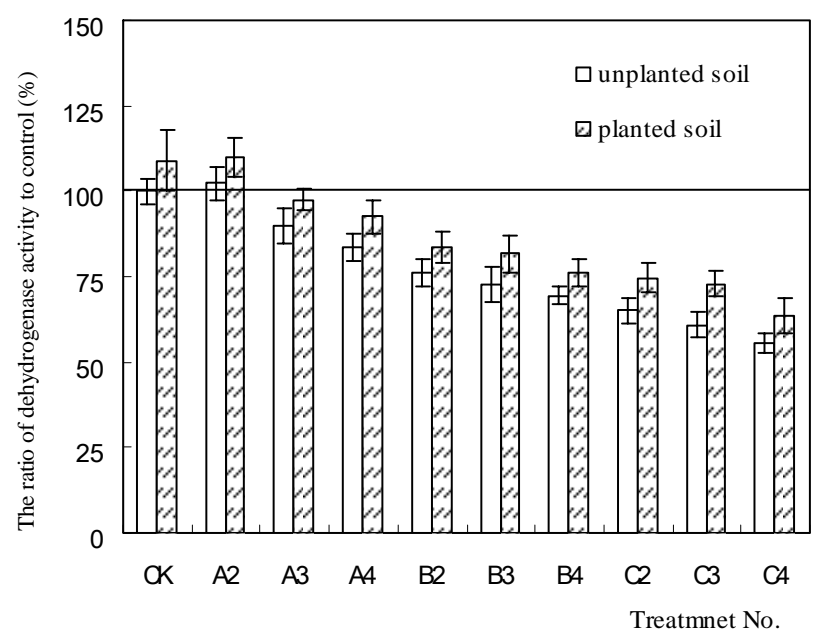

Figure 3. Dehydrogenase activity in unplanted and planted soils 


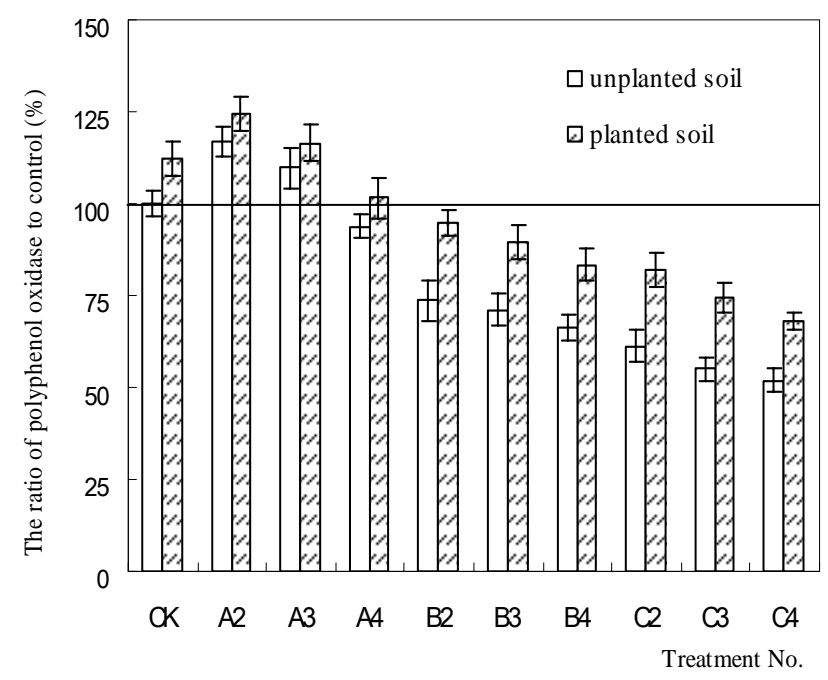

Figure 4. Polyphenol oxidase activity in unplanted and planted soils

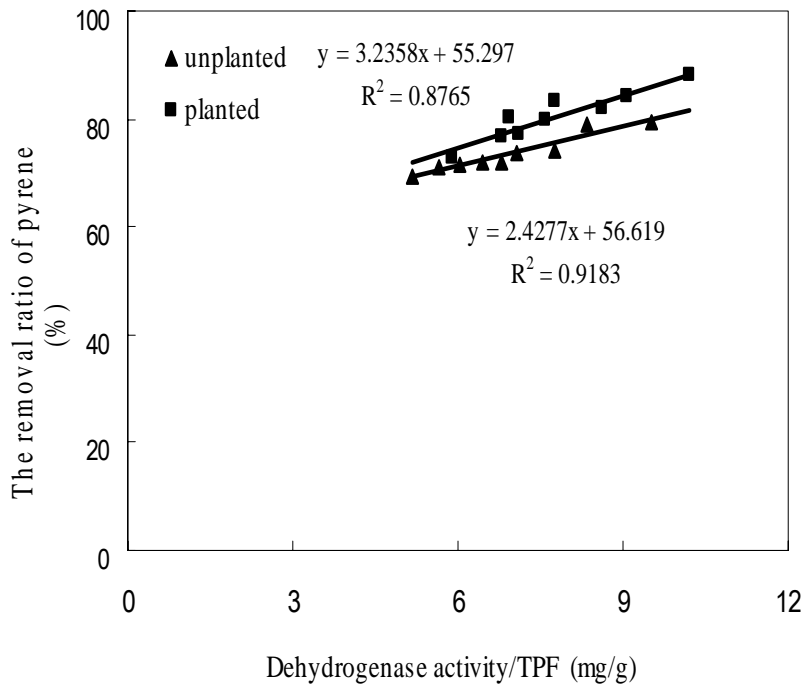

Figure 5. Correlation between the removal ratio of pyrene and dehydrogenase activity in unplanted and planted soils

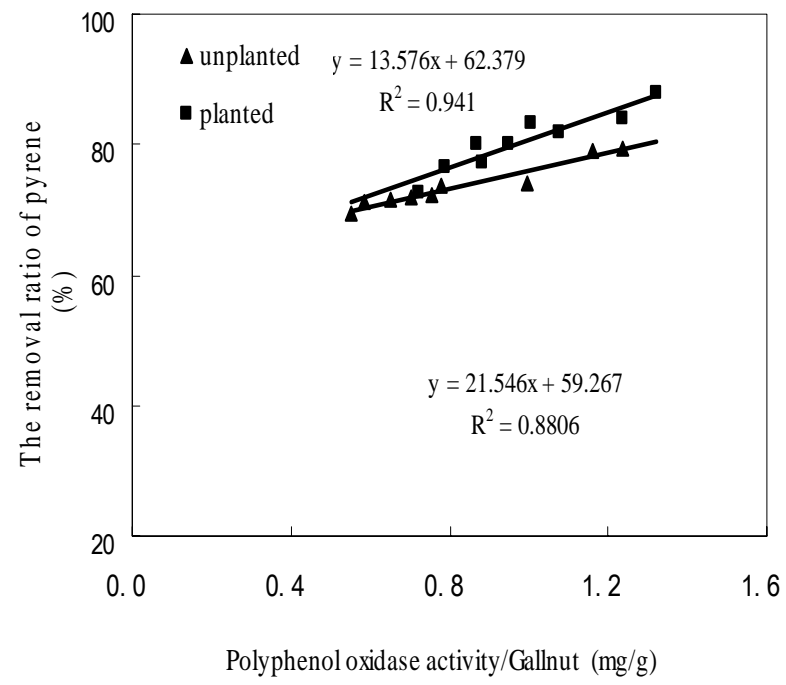

Figure 6. Correlation between the removal ratio of pyrene and polyphenol oxidase activity in unplanted and planted soils 


\section{CONCLUSIONS}

The dissipation of pyrene in both sole and cadmium co-contaminated soil was enhanced by the presence of vegetation. Although the presence of cadmium stimulated the accumulation of pyrene in the roots and shoots of maize, the contribution of plant off-take was less than $0.3 \%$. In contrast, plant-promoted biodegradation was the predominant contribution to the plant-enhanced dissipation of soil pyrene with cadmium co-contamination. The inhibitory effect of cadmium on the dissipation of pyrene and enzyme activity increased with the Cd load, which suggested that the change in microbial activity or plant root physiology under cadmium stress was not beneficial to the dissipation of pyrene. Significant positive correlations were found between the enzyme activity of dehydrogenase or polyphenol oxidase and the removal ratio of pyrene in soils, which implies that the reduced degradation activity of microorganisms or enzyme was responsible for the significantly lower level of pyrene dissipation. It is conceivable that maize root exudates, which have physiological and biochemical functions, had a beneficial effect on soil biota and enzyme activity, alleviating the toxicity of soil pollution with cadmium and pyrene, thereby improving the pollutant degradation. These findings provide preliminary evidence for the potential of maize CT38 in the remediation of pyrene in medium concentrations of cadmium and pyrene co-contaminated soil.

\section{ACKNOWLEDGMENTS}

This work was funded as part of a Key Project of National Natural Science Foundation of China (40730741), the Technology Research Program of Guangzhou Environmental Protection Bureau, China (2006143), the Project Supported by Guangxi Science Foundation (0832017) and the Research funds of The Guangxi Key Laboratory of Environmental Engineering, Protection and Assessment. We thank Prof. James Irish at South China University of Technology for editing the manuscript.

\section{REFERENCES}

Amor L., Kennes C., Veiga M.C., (2001), Kinetics of inhibition in the biodegradation of monoaromatic hydrocarbons in presence of heavy metals, Bioresource Technology, 78, 181-185.

Andreoni V., Cavalca L., Rao M.A., Nocerino G., Bernasconi S., Dell-Amico E., Colombo M., Gianfreda L., (2004), Bacterial communities and enzyme activities of PAHs polluted soils, Chemosphere, 57, 401-412.

Casida L.E., Kleın Jr., D.A., Santoro T., (1964), Soil dehydrogenase activity, Soil Science, 98, 371-376.

Gao Y.Z. and Zhu L.Z., (2004), Plant uptake, accumulation and translocation of phenanthrene and pyrene in soils, Chemosphere, 55, 1169-1178.

Garbisu C. and Alkorta I., (2001), Phytoextraction: a cost-effective plant-based technology for the removal of metals from the environment, Bioresource Technology, 77, 229-236.

Kaimi E., Mukaidani T., Miyoshi S., Tamaki M., (2006), Ryegrass enhancement of biodegradation in diesel-contaminated soil, Environmental and Experimental Botany, 55, 110-119.

Kipopoulou A.M., Manoli E., Samara C., (1999), Bioconcentration of PAHs in vegetables grown in an industrial area, Environmental Pollution, 6, 369-380.

Kuo C.W. and Genthner B.R.S., (1996), Effect of added heavy metal ions on biotransformation and biodegradation of 2-chlorophenol and 3-chlorobenzoate in anaerobic bacterial consortia, Applied and Environmental Microbiology, 62, 2317-2323.

Lin Q., Wang Z.W., Ma S., Cheng Y.X., (2006), Evaluation of dissipation mechanisms by Lolium perenne L. and Raphanus sativus for pentachlorophenol (PCP) in copper co-contaminated soil, Science of the Total Environment, 368, 814-822.

Lin Q., Shen K.L., Zhao H.M., Li W.H., (2008), Growth response of Zea mays L. in pyrene-copper co-contaminated soil and the fate of pollutants, Journal of Hazardous Materials, 150, 515-521.

Liste H.H., Alexander M. (2000), Accumulation of phenanthrene and pyrene in rhizosphere soil, Chemosphere, 40, 11-14.

Ma Y., Zhang J.Y., Wong M.H., (2003), Microbial activity during composting of anthracene-contaminated soil, Chemosphere, 52, 1505-1513.

Maliszewska-Kordybach B. and Smreczak B., (2003), Habitat function of agricultural soils as affected by heavy metals and polycyclic aromatic hydrocarbons contamination, Environment 
International, 28, 719-728.

Margesin R., Zimmerbauer A., Schinner F., (2000), Monitoring of bioremediation by soil biological activities, Chemosphere, 40, 339-346.

Namkoong W., Hwang E.Y., Park J.S., Choi J.Y. (2002), Bioremediation of diesel-contaminated soil with composting, Environmental Pollution, 119, 23-31.

Olson P.E., Wong T., Leigh M.B., Fletcher J.S., (2003), Allometric modeling of plant root growth and its application in rhizosphere remediation of soil contaminants, Environmental Science and Technology, 37, 638-643.

Polder M.D., Hulzebos E.M., Jager D.T., (1995), Validation of models on uptake of organic chemicals by plant roots, Environmental Toxicology and Chemistry, 14, 1615-1623.

Sandrin T.R. and Maier R.M., (2002), Effect of pH on cadmium toxicity, speciation, and accumulation during naphthalene biodegradation, Environmental Toxicology and Chemistry, 21, 2075-2079.

Stanislaw B., Jolanta E.B., Patryk O., (2004), Enzymatic activity in an airfield soil polluted with polycyclic aromatic hydrocarbons, Geoderma, 118, 221-232.

Trapp S., Matthies M., Scheunert I., Topp E.M., (1990), Modeling the bioconcentration of organic chemicals in plants, Environmental Science and Technology, 24, 1246-1252.

Zhang H., Dang Z., Yao L.X., (2007), Eco-toxicologic effect of cadmium and pyrene combined and simplex pollution on soil microbe, Journal of Agro-Environment Science, 26, 2225-2230 (in Chinese).

Zhou J.M., Dang Z., Tao X.Q., Zhou Y.Z., (2005), Influence of NTA on Accumulation and Subcellular Distribution of Copper and Zinc in Corn (Zea mays), Environmental Science, 26, 127-131 (in Chinese).

Zhou J.M., Dang Z., Cai M.F., (2007), Soil Heavy Metal Pollution Around the Dabaoshan Mine, Guangdong Province, China, Pedosphere, 17, 588-594. 